\title{
Role and mechanism of chaperones calreticulin and ERP57 in restoring trafficking to mutant HERG-A561V protein
}

\author{
YUJIA WU ${ }^{1}$, XIAOYAN HUANG ${ }^{2,3}$, ZEQUN ZHENG $^{1}$, XI YANG $^{2,3}$, YANNA BA $^{2}$ and JIANGFANG LIAN ${ }^{2,3}$ \\ ${ }^{1}$ School of Medicine, Ningbo University, Ningbo, Zhejiang 315211; ${ }^{2}$ Department of Cardiology, Lihuili Hospital, \\ Ningbo University; ${ }^{3}$ Ningbo Institute of Innovation for Combined Medicine and Engineering, \\ Ningbo, Zhejiang 315100, P.R. China
}

Received January 19, 2021; Accepted May 20, 2021

DOI: $10.3892 /$ ijmm.2021.4992

\begin{abstract}
Long QT syndrome type 2 is caused by a mutation in the human-ether-a-go-go-related gene (HERG) gene encoding the rapidly activating delayed rectifier K-current. HERG is a key cell membrane glycoprotein; however, whether the maturation process of HERG protein involves key molecules derived from the calnexin $(\mathrm{CNX}) /$ calreticulin (CRT) cycle and how these molecules work remains unknown. Using western blotting, the present study screened the key molecules CNX/CRT/endoplasmic reticulum protein 57 (ERP57) involved in this cycle, and it was revealed that the protein expression levels of CNX/CRT/ERP57 in wild-type (WT)/A561V cells were increased compared with those in WT cells $(\mathrm{n}=3 ; \mathrm{P}<0.05)$. Additionally, a co-immunoprecipitation experiment was used to reveal that the ability of CNX/ERP57/CRT to interact with HERG was significantly increased in A561V and WT/A561V cells $(\mathrm{n}=3 ; \mathrm{P}<0.05)$. A plasmid lacking the bb' domain of ERP57 was constructed and it was demonstrated that the key site of ERP57 binding to CRT and immature HERG protein is the bb' domain. The whole-cell patch-clamp technique detected that the tail current density increased by $46 \%$ following overexpression of CRT and by 53\% following overexpression of ERP57 in WT/A561V cells. Overexpression of CRT and ERP57 could increased HERG protein levels on the membrane detected by confocal imaging. Furthermore, overexpression of ERP57 and CRT proteins could restore the HERG-A561V mutant
\end{abstract}

Correspondence to: Dr Jiangfang Lian, Department of Cardiology, Lihuili Hospital, Ningbo University, 57 Xingning Road, Ningbo, Zhejiang 315100, P.R. China

E-mail: hjmpin@163.com

Abbreviations: CNX, calnexin; CRT, calreticulin; ERP57, endoplasmic reticulum protein 57; ER, endoplasmic reticulum; ERQC, ER quality control; HERG, human-ether-a-go-go-related gene; $I K r$, rapidly activating delayed rectifier K-current; LQTS, long QT syndrome; LQT2, long QT syndrome type 2; UGGT1, UDP-glucose: glycoprotein glucosyltransferase 1

Key words: LQTS, CNX/CRT cycle, chaperones ERP57/CNX/CRT, HERG-A561V mutation protein trafficking process and rescue the dominant-negative suppression of WT. Overall, ERP57/CRT served a crucial role in the HERG-A561V mutant protein trafficking deficiency and degradation process.

\section{Introduction}

Long-QT syndrome (LQTS) is a hereditary cardiac ion channel disease with 17 clinical subtypes characterized by potentially fatal arrhythmia and sudden cardiac death (1). Long QT syndrome type 2 (LQT2) is caused by a human-ether-a-go-go-related gene (HERG) mutation (2). HERG is located at 7q35-36 and encodes the cardiac Kv11.1 potassium channel, which rapidly activates the delayed rectifier potassium current $(I K r)$ (3). The HERG channel is an essential cardiac ion channel whose mutations can cause partial or complete reduction of $I K r$ current and delayed ventricular repolarization (4). Four possible mechanisms have been identified for the loss of HERG channel function caused by HERG gene mutations: Channel protein synthesis defects, trafficking barriers after protein synthesis, gate control defects and current conduction defects (5). A previous study has reported that a heterozygous missense mutation (A561V) linked to LQT2, syncope and epilepsy was identified in the S5/pore region of HERG protein (6). HERG-A561V mutation causes the HERG channel protein to change conformation and remain in the endoplasmic reticulum (ER), preventing it from maturing and trafficking to the plasma membrane where it can serve a role (7).

The ER quality control (ERQC) system, which mediates folding and trafficking of channel proteins in the ER, is fundamental to folding newly synthesized proteins (8). The ERQC system monitors HERG and other nascent proteins and facilitates their exit from the ER for the following processing stage (9). The calnexin (CNX)/calreticulin (CRT) cycle, composed of lectin-like molecular chaperones CNX and CRT, is an essential part of the ERQC system that depends on modifying protein glycosylation and sugar chain structures in the ER (10). The CNX/CRT cycle is one of the important monitoring mechanisms for protein folding and assembly (11). The disulfide bond isomerase ER protein 57 (ERP57), involved in the CNX/CRT cycle, catalyzes the oxidation and isomerization of disulfide bonds in glycoproteins and 
binds to CNX/CRT glycoproteins $(12,13)$. The formation of transient disulfide bonds assists protein folding (14). ERP57, a prominent multifunctional member of the protein disulfide isomerase (PDI) family, is detected at various levels in multiple cellular locations, including the ER, nucleus, cytoplasm, mitochondria and plasma membrane (15). ERP57 has 505 amino acids and consists of four domains: A-b-b'-a', N-terminal signal sequence and Gln-Glu-Asp-Leu C-terminal ER retention/search motif (16). Both the a and a' domains have active sites similar to thioredoxin, and each region has a redox-active Cys-Gly-His-Cys catalytic sequence (15). The b and $b^{\prime}$ domains contain binding sites for CRT and CNX (17). The catalytically inactive central domains, $b$ and $b$ ', serve a vital role in the specific functionality of ERP57 to bind proteins and assist in their folding, and contain binding sites for CNX and CRT (18).

At present, no study has described how to influence the trafficking of mutant HERG proteins by regulating key molecular chaperones in the CNX/CRT cycle. Our previous study verified that the two chaperone proteins CNX and CRT arrest the export of mutant HERG from the ER and empower it to refold into the correct native conformation and thus serve a role in preventing trafficking and degrading defective HERG mutant protein (19). The present study further evaluated the roles of CNX, CRT and ERP57 in trafficking the defective HERG- A561V mutant protein.

\section{Materials and methods}

Cells, cDNA and cell culture. Experiments were performed using the 293 cell line obtained from The Cell Bank of Type Culture Collection of The Chinese Academy of Sciences. Wild-type (WT)-HERG was expressed using pcDNA3 vector (Invitrogen; Thermo Fisher Scientific, Inc.). A561V was produced by site-directed mutagenesis of WT cDNA and then subcloned into WT pcDNA3 vector at the BstEII/XhoI restriction sites. The WT, heterozygous and mutant cell lines were constructed by transiently transfecting pcDNA3-WT, pcDNA3-WT/pcDNA3-A561V and pcDNA3-A561V, respectively. At $24 \mathrm{~h}$ after expression of the aforementioned plasmid, pcDNA3-Vector (negative control), pcDNA3-CRT (CALR; NM_004343) and pcDNA3-ERP57 (PDIA3; NM_005313) were transfected to overexpress CRT and ERP57. pL-short hairpin RNA-Vector (negative control) and pL-short hairpin RNA-CRT (CALR-RNAi:5'-GATCCCctCTGTGAGACT CGAGAACTTCTCGAGAAGTTCTCGAGTCTCACAGATT TTT-3') were transfected to reduce CRT expression. Domain deletion was implemented by transfecting pcDNA3-ERP57-b domain deletion [PDIA3, NM_005313(del244-357aa)], pcDNA3-ERP57-b' domain deletion [PDIA3, NM_005313(del135-240aa)] or pcDNA3-ERP57-bb' domain deletion [PDIA3, NM_005313(del135-357aa)] (all plasmids were obtained from Shanghai GeneChem Co., Ltd.) into the heterozygous cells. TransIT-2020 (Mirus Bio, LLC) diluted in Opti-MEM I reducing serum medium (Gibco; Thermo Fisher Scientific, Inc.) was used to transfect a total of $2.5 \mu \mathrm{g}$ of plasmid into the cells at room temperature $\left(23 \pm 2^{\circ} \mathrm{C}\right)$ for $48 \mathrm{~h}$, according to the manufacturer's instructions. After $48 \mathrm{~h}$, the transfected cells were used for experiments. All cells were cultured in high glucose DMEM (Gibco; Thermo Fisher Scientific, Inc.) containing 10\% FBS (Bovogen Biologicals Pty, Ltd.), and kept in a humid $5 \% \mathrm{CO}_{2}$ incubator at $37^{\circ} \mathrm{C}$.

Reverse transcription-quantitative PCR (RT-qPCR). Total RNA was isolated from the treated 293 cells using TRIzol reagent (Sangon Biotech Co., Ltd.). Reverse transcription was conducted using TransScript ${ }^{\circledR}$ All-in-One First-Strand cDNA Synthesis SuperMix for qPCR (One-Step gDNA Removal) (cat. no. AT341-01; TransGen Biotech Co., Ltd.) at $42^{\circ} \mathrm{C}$ for $15 \mathrm{~min}$ and heating at $85^{\circ} \mathrm{C}$ for $5 \mathrm{sec}$. Subsequently, qPCR was performed using the SYBR-Green Real-Time PCR kit (cat. no. TSE202; TsingKe Biological Technology) according to the manufacturer's protocols. The PCR amplification reaction was as follows: $95^{\circ} \mathrm{C}$ for $1 \mathrm{~min}$, followed by 45 cycles of $95^{\circ} \mathrm{C}$ for $10 \mathrm{sec}$ and $60^{\circ} \mathrm{C}$ for $60 \mathrm{sec}$. Relative quantification was calculated using the $2^{-\Delta \Delta \mathrm{Cq}}$ method, with GAPDH being used to normalize mRNA expression (20). The primers used for PCR were as follows: GAPDH forward, 5'-GGTGTGAAC CATGAGAAGTAT GA-3' and reverse, 5'-GAGTCCTTCCAC GATACCAAAG-3'; HERG forward, 5'-AGGACAAGTATG TGACGGCG-3' and reverse, 5'-AGGGAGCCAATGAGC ATGAC-3'; ERP57 forward, 5'-GGAGGAGTTCTCGCGTGA TG-3' and reverse, 5'-CAGGCCCATCATTGCTCTCT-3'; and CRT forward, 5'-GGCAGATCGACAACCCAGAT-3' and reverse, 5'-GATGGTGCCAGACTTGACCT-3'.

Western blotting. 293 cells expressing HERG in 35-mm diameter culture dishes were harvested for analysis at $48 \mathrm{~h}$ after transient transfection. Resuspended cells were washed with ice-cold PBS. Cell pellets were solubilized in ice-cold RIPA buffer (Beijing Solarbio Science \& Technology Co., Ltd.) containing the protease inhibitor PMSF (Beijing Solarbio Science \& Technology Co., Ltd.), incubated on ice for $30 \mathrm{~min}$ and centrifuged at $13,800 \mathrm{x} \mathrm{g}$ for $15 \mathrm{~min}$ at $4^{\circ} \mathrm{C}$ to pellet detergent-insoluble cell debris. The supernatant was stored at $-80^{\circ} \mathrm{C}$, and the proteins contents were quantified using the BCA protein assay kit (Thermo Fisher Scientific, Inc.). Subsequently, $30 \mu \mathrm{g} /$ lane of protein was separated by 6\% SDS-PAGE, and then transferred to PVDF membranes (MilliporeSigma). Membranes were blocked for $1 \mathrm{~h}$ at room temperature with blocking solution (5\% non-fat dry milk powder and $0.2 \%$ Tween-20 in TBS). The membranes were incubated with rabbit polyclonal anti-HERG (1:400; cat. no. APC-109; Alomone Labs), mouse monoclonal anti-CNX (1:2,000; cat. no. ab92573; Abcam), anti- $\beta$-tubulin (reference protein in the cytoplasm; 1:2,000; cat. no. K200059M; Beijing Solarbio Science \& Technology Co., Ltd.), anti-GAPDH (reference protein for the whole cell; 1:3,000; cat. no. K200057M; Beijing Solarbio Science \& Technology Co., Ltd.), anti-Na/K ATPase (reference protein for cell membranes; 1:10,000; cat. no. ab254025; Abcam), anti-ERP57 (1:1,000; cat. no. ab13506; Abcam) and anti-CRT (1:2,000; cat. no. ab22683; Abcam) antibodies at $4^{\circ} \mathrm{C}$ overnight. After three washes with TBS with $0.3 \%$ Tween-20, the membrane was probed with a goat anti-mouse antibody HRP-conjugated secondary antibody (1:2,000; cat. no. SE131; Beijing Solarbio Science \& Technology Co., Ltd.) or goat anti-rabbit antibody (1:2,000; cat. no. SE134; Beijing Solarbio Science \& Technology Co., Ltd.) for $1 \mathrm{~h}$ at room temperature. Western blots were visualized using WesternBright ECL chemiluminescent substrate 
(Advansta, Inc.) according to manufacturer's protocol using an ImageQuant LAS 500 imager (General Electric). Band densities were quantitated using ImageJ (v1.51; National Institutes of Health).

Co-immunoprecipitation of CNX, CRT and ERP57 with immature HERG. 293 cells expressing HERG in 6-well cell culture plates were harvested at $48 \mathrm{~h}$ after transient transfection as aforementioned. Subsequently, the IP/CoIP kit (cat. no. abs955; Absin (Shanghai) Biotechnology Co., Ltd.) was used. After centrifugation at $14,000 \times \mathrm{g}$ for $10 \mathrm{~min}$ at $4^{\circ} \mathrm{C}$, the supernatant was the cell division product. Subsequently, beads ( $5 \mu 1$ Protein A and $5 \mu$ l Protein G) were added to $500 \mu \mathrm{l}$ (containing 200-1,000 $\mu \mathrm{g}$ total protein) cell lysate. CNX-HERG, CRT-HERG and ERP57-HERG complexes were immunoprecipitated by incubation with $2 \mu \mathrm{g}$ antibody against CNX (cat. no. ab92573; Abcam), CRT (cat. no. ab22683; Abcam) and ERP57 (cat. no. ab13506; Abcam), respectively, at $4^{\circ} \mathrm{C}$ overnight. Furthermore, $5 \mu \mathrm{l}$ Protein A and $5 \mu \mathrm{l}$ Protein $\mathrm{G}$ were added and mixed gently at $4^{\circ} \mathrm{C}$ for $1-3 \mathrm{~h}$, then the precipitate was washed with $0.5 \mathrm{ml} 1 \mathrm{X}$ Wash buffer (from the IP/CoIP kit), centrifuged at $12,000 \times \mathrm{g}$ for $1 \mathrm{~min}$ at $4^{\circ} \mathrm{C}$, and the precipitate was retained. Subsequently, 20-40 $\mu \mathrm{l} 1 \mathrm{X}$ SDS was added to the precipitate, and the sample was heated to $100^{\circ} \mathrm{C}$ for $5 \mathrm{~min}$. This was followed by analysis by western blotting and band densities were quantitated using ImageJ.

Immunofluorescence and confocal imaging. 293 cells were seeded at a density of $1.0 \times 10^{5}$ cells per well of a 6 -well plate coverslips and transiently transfected with pcDNA3-WT, pcDNA3-A561V and pcDNA3-WT/A561V plasmids. After $24 \mathrm{~h}$ of incubation, pcDNA3-CRT and pcDNA3-ERP57 were transiently transfected into the cells, which were cultured for an additional $48 \mathrm{~h}$. The cells were fixed with $4 \%$ paraformaldehyde for $30 \mathrm{~min}$ at $37^{\circ} \mathrm{C}$, permeabilized with $0.5 \%$ Triton X-100 for 10 min and blocked with $5 \%$ goat serum (all from Beijing Solarbio Science \& Technology Co., Ltd.) at room temperature for $1 \mathrm{~h}$. Cells were labeled with rabbit polyclonal anti-HERG antibody (1:200; cat. no. APC-109; Alomone Labs) at $4^{\circ} \mathrm{C}$ overnight and then incubated with FITC-conjugated goat anti-rabbit IgG immunofluorescent secondary antibody (1:1,000; cat. no. SA00013-2; ProteinTech Group, Inc.) and phalloidin (1:1,000; cat. no. AC18L022; Shanghai Life iLab Bio Technology Co., Ltd.) at room temperature for $1 \mathrm{~h}$. Signals were captured using a Leica TCS SP8 confocal laser scanning microscope (Leica Microsystems, Inc.).

Whole-cell patch-clamp recordings. 293 cells were collected $48 \mathrm{~h}$ after transfection (DNA plasmid only) to examine differences in tail currents of WT, A561V and WT/A561V and the effect of overexpression of ERP57 and CRT on WT/A561V using the patch-clamp technique. A pipette with an end resistance of 2-5 M $\Omega$, when filled with the internal solution, was used to record membrane currents in a whole-cell recording configuration, as described in previous studies $(21,22)$. The electrodes were connected to an Axopatch 700B amplifier (Molecular Devices, LLC), and currents were analog filtered at a frequency of $2 \mathrm{kHz}$ and digitized by an analog-to-digital converter (DigiData1440A; Molecular Devices, LLC). For this experiment, pCLAMP version 10.3 software (Molecular
Devices, LLC) was used to edit the stimulation program, record the current, and analyze and measure the raw data. Excel 2016 (Microsoft Corporation) and Origin7.5 (OriginLab) software were used to perform statistics and map the original data, activate the current and tail current, and calculate current density according to battery capacitance, thereby eliminating the impact of battery size on data.

Statistical analysis. GraphPad Prism 7.0 software (GraphPad Software, Inc.) was used to perform statistical analysis. All experiments were performed at least in triplicate and data are presented as the mean \pm SD. Differences between two groups were analyzed using an unpaired Student's t-test and differences among three or more groups were analyzed using one-way ANOVA followed by Tukey's post hoc test. $\mathrm{P}<0.05$ was considered to indicate a statistically significant difference.

\section{Results}

HERG-A561V mutation upregulates CNX/CRT/ERP57 expression. To improve the understanding of maturation and trafficking of HERG protein in cells expressing WT, mutant and heterozygous HERG, pcDNA3-WT, pcDNA3-A561V or pcDNA3-WT/A561Vplasmids were transiently transfected into 293 cells and the successful transfection was demonstrated by RT-qPCR (Fig. 1A). At $48 \mathrm{~h}$ post-transfection, the protein was extracted from cells for western blot analysis, and the protein expression levels of CNX, CRT and ERP57 were detected. As shown in (Fig. 1E-H) the expression levels of CNX/CRT/ERP57 were significantly increased in the A561V and WT/A561V groups $(\mathrm{P}<0.05)$. WT-transfected cells exhibited two protein bands for HERG, of which the upper band at $155 \mathrm{kDa}$ represents a mature, fully glycosylated glycoprotein form of HERG, which is transported to the cell membrane surface. The lower band at $135 \mathrm{kDa}$ represents a core-glycosylated immature form of HERG, and the band at $132 \mathrm{kDa}$ is the precursor of immature form of HERG protein, all located in the ER. As shown in (Fig. 1B-D) immature forms of HERG (135 kDa) were significantly increased in the A561V and WT/A561V groups compared with the WT group $(\mathrm{P}<0.05)$. Furthermore, the mature form expression of HERG protein $(155 \mathrm{kDa})$ was significantly reduced in the A561V group compared with the WT group $(\mathrm{P}<0.05)$, and $155 \mathrm{kDa}$ HERG protein expression was not increased in the WT/A561V group compared with the WT group $(\mathrm{P}>0.05)$. These results indicated that co-expression of WT and A561V will not lead to complete loss of HERG function related to the negative dominant effect of the A561V mutation site and molecular chaperone CNX/ERP57/CRT serves a role in this process.

Tail current of WT/A561V is suppressed but it does not disappear completely. The localization and protein trafficking of HERG protein in cells expressing WT, A561V and WT/A561V were examined by immunostaining and confocal imaging (Fig. 2A-C). The confocal image clearly revealed that WT protein was expressed on the cell surface (white arrows) and in the cytoplasm (yellow arrows). By contrast, A561V and WT/A561V proteins were mainly expressed in the cytoplasm. Specifically, the mutant HERG protein was mainly retained in the ER. No tail current was observed in A561V cells but this was present 


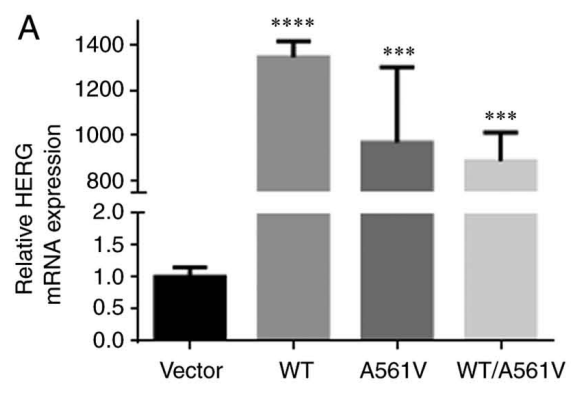

C

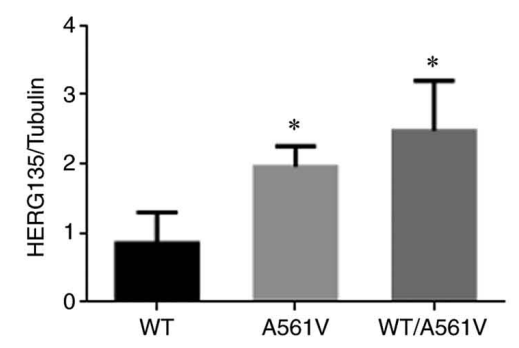

$E$
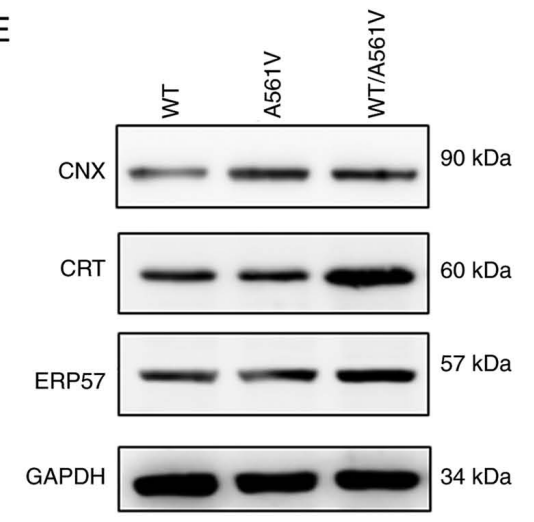

G

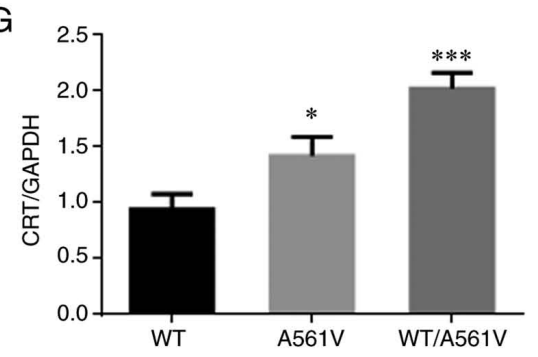

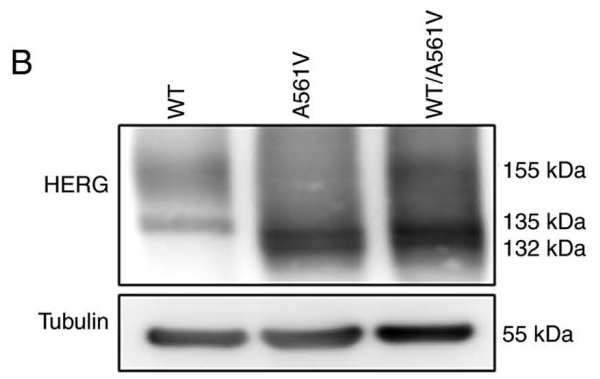

D

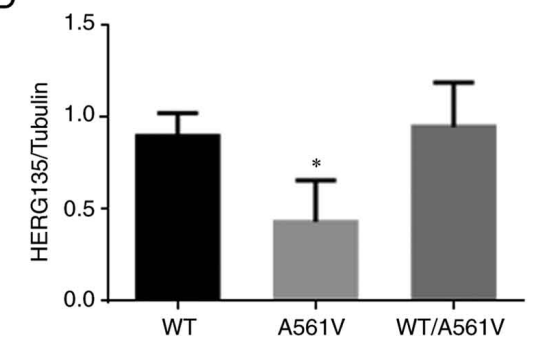

F
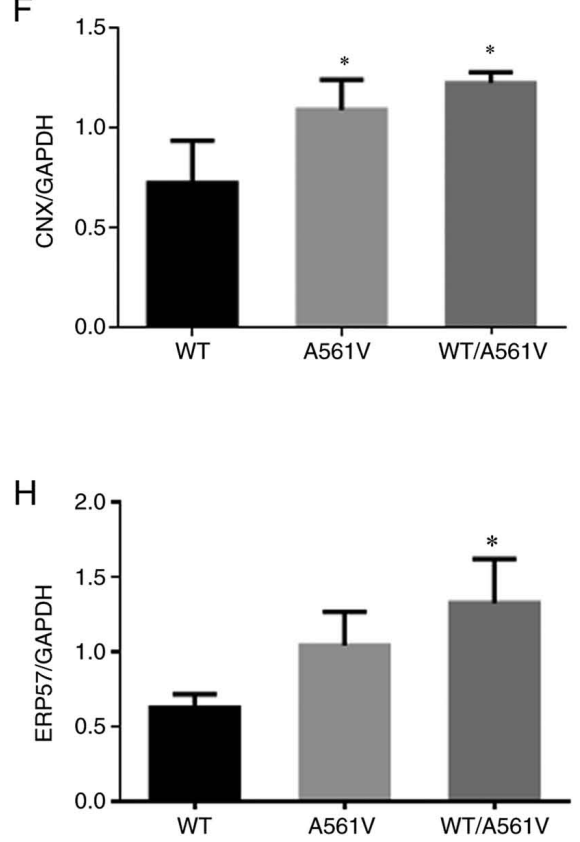

Figure 1. HERG-A561V mutation upregulates CNX/CRT/ERP57 expression. (A) Relative HERG mRNA expression in cells transfected with WT, A561V and WT/A561V. ${ }^{* * *} \mathrm{P}<0.001,{ }^{* * * * *} \mathrm{P}<0.0001$ vs. Vector. (B) HERG protein expression in cells transfected with WT, A561V and WT/A561V were detected by western blotting. (C) Optical density analysis of immature ( $135 \mathrm{kDa})$ forms of HERG protein. ${ }^{*} \mathrm{P}<0.05 \mathrm{vs}$. WT. (D) Optical density analysis of mature (155 kDa) forms of HERG protein. ${ }^{*} \mathrm{P}<0.05$ vs. WT. (E) CNX/CRT/ERP57 protein expression in cells transfected with WT, A561V and WT/A561V were detected by western blotting. (F) Optical density analysis of CNX protein expression. " $\mathrm{P}<0.05$ vs. WT. (G) Optical density analysis of CRT protein expression. " $\mathrm{P}<0.05$, ${ }^{* * * *} \mathrm{P}<0.001$ vs. WT. (H) Optical density analysis of ERP57 protein expression. " $\mathrm{P}<0.05$ vs. WT. Data are presented as the mean \pm SD; $\mathrm{n}=3$ in each group. One-way ANOVA was used to analyze the data. CNX, calnexin; CRT, calreticulin; ERP57, endoplasmic reticulum protein 57; HERG, human ether-a-go-go-related gene; WT, wild-type HERG group; A561V, A561V-HERG mutation group; WT/A561V, heterozygous HERG group.

in WT/A561V cells. The tail current density in WT/A561V cells $(13.30 \pm 3.23 \mathrm{pA} / \mathrm{pF})$ was $56 \%$ lower than that of WT cells (30.49 $\pm 8.67 \mathrm{pA} / \mathrm{pF} ; \mathrm{n}=6 ; \mathrm{P}<0.05)$ (Fig. 2H). In Fig. 2I, the normalized data of the tail currents were plotted against the test potential and fitted to a Boltzmann function. The half-maximal activation voltage (V1/2) in WT/A561V cells was-17.19709 $\pm 2.22513 \mathrm{mV}$, whereas that in WT cells was-23.76787 $\pm 0.4569 \mathrm{mV} \quad(\mathrm{n}=6$; $\mathrm{P}>0.05)$. A similar trend was seen in the slope factor $\mathrm{k}$ values of WT/A561V cells $(7.87613 \pm 1.95185 \mathrm{mV})$ compared with WT cells $(9.02434 \pm 0.39344 \mathrm{mV})(\mathrm{n}=6 ; \mathrm{P}>0.05)$. Therefore, there was no significant difference in activation phase properties of WT and WT/A561V protein channels. As shown, the heterozygous channel did not completely lose its function. If normal transportation can be partially restored after refolding, the heterozygous channel may still serve a certain compensatory role. Therefore, it was concluded that the mutant HERG protein could not be transported to the membrane to perform its function. HERG function did not completely disappear in heterozygous cells, and some HERG proteins were still transported to the cell membrane. 
A

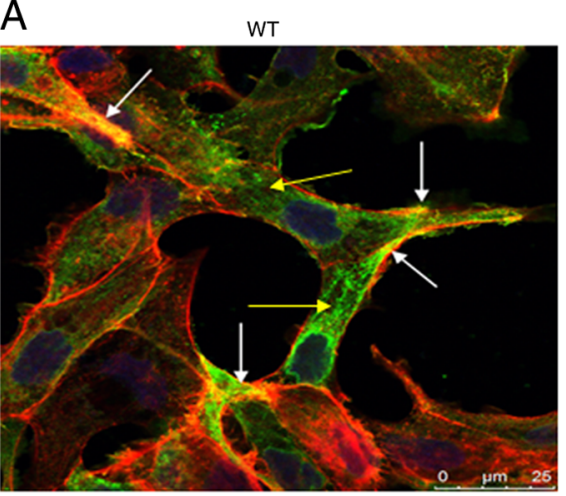

B

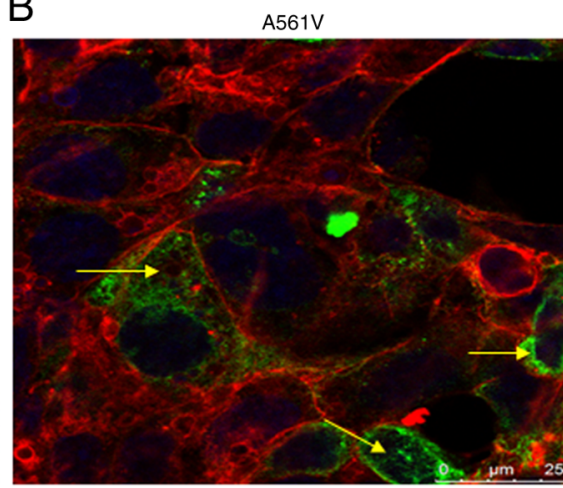

D

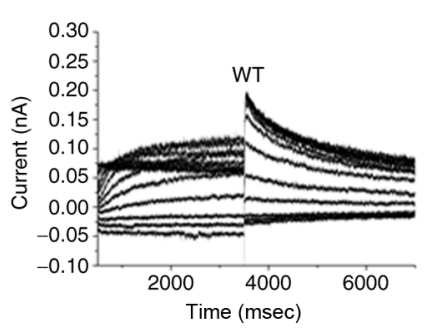

G

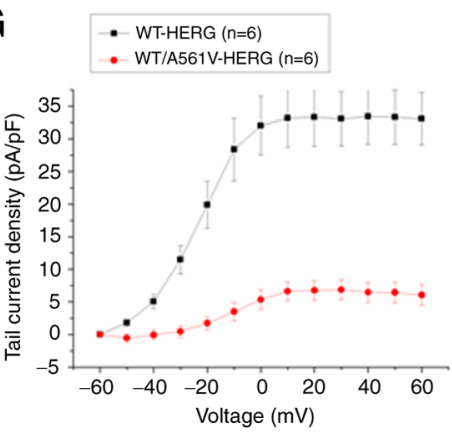

E

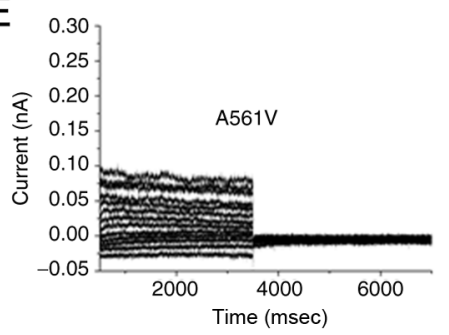

$\mathrm{H}$

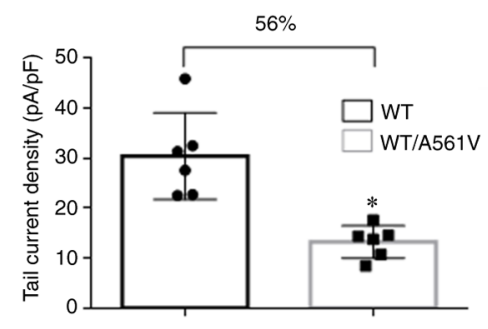

C

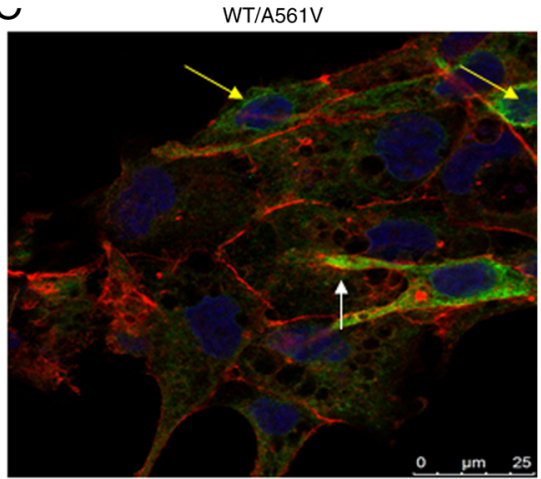

F

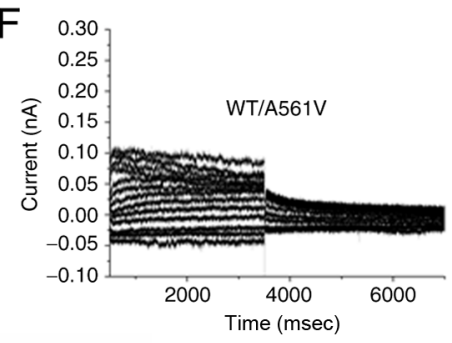

I

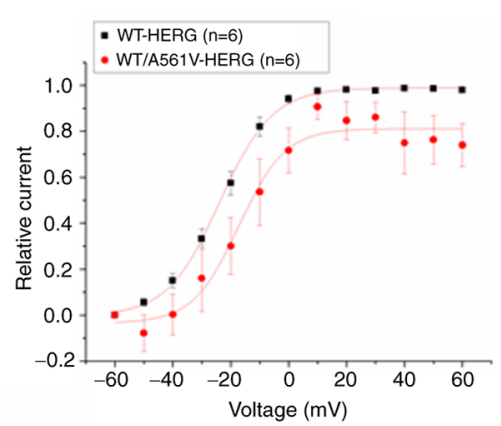

Figure 2. Tail current of WT/A561V is suppressed but it does not disappear completely. (A) Confocal imaging of WT channel in 293 cells (60X confocal special oil lens). (B) Confocal imaging of A561V channel in 293 cells (60X confocal special oil lens). (C) Confocal imaging of WT/A561V channel in 293 cells (60X confocal special oil lens). 293 cells were transfected with WT, A561V and WT/A561V plasmids and stained with anti-HERG antibody (green). DAPI-stained nuclei (blue) and phalloidin-stained actin filaments (red) were used to identify the nucleus and plasma membrane, respectively. WT was located in the plasma membrane (indicated by the white arrows) and cytoplasm (indicated by the yellow arrows). (D) WT tail current amplitudes. (E) A561V tail current amplitudes. (F) WT/A561V tail current amplitudes. (G) Current-voltage relationships for tail currents amplitudes of WT and WT/A561V. (H) Statistical graph of tail current amplitudes, WT/A561V was 56\% lower compared with the WT group ( $\mathrm{n}=6$; $\left.{ }^{*} \mathrm{P}<0.05\right)$. (I) Amplitudes of tail currents of WT or WT/A561V channel plotted as a function of the test potential and fitted to a Boltzmann function (n=6). HERG, human ether-a-go-go-related gene; WT, wild-type HERG group; A561V, A561V-HERG mutation group; WT/A561V, heterozygous HERG group.

Mutual binding ability of A561V and WT/A561V proteins with molecular chaperones CNX/ERP57/CRT is increased compared with that of the WT group. To clarify the role of key molecular chaperones CNX, CRT and ERP57 in mediating A561V folding in the CNX/CRT cycle, the present study used immunoprecipitation to detect HERG protein binding to molecular chaperones CNX, CRT and ERP57 in cells expressing WT, A561V and WT/A561V. The physical association of the HERG channel with chaperones was determined by immunoprecipitation with anti-CNX, anti-CRT and anti-ERP57 antibodies followed by western blot analysis with anti-HERG, anti-CNX, anti-CRT and anti-ERP57 antibodies (Fig. 3). In A561V and WT/A561V cells, CNX/CRT/ERP57 and immature forms of HERG protein binding increased $(\mathrm{P}<0.05)$. Simultaneously, the present study also revealed that, in WT/A561V cells, ERP57 binding to CRT protein was significantly enhanced compared with the WT group $(\mathrm{P}<0.05)$. $b b^{\prime}$ domain of ERP57 is a key domain that binds to HERG and CRT proteins. As shown in Fig. 4A-D, b and b' are key domains required for ERP57 to bind to HERG and CRT proteins and promote proper protein folding. After the modified ERP57 was expressed in WT/A561V cells, ERP57 in the bb' domain deletion group was identified to exhibit enhanced binding to HERG and CRT proteins compared with the Vector group $(\mathrm{P}<0.05)$, and there was no significant difference in binding among the remaining groups $(\mathrm{P}>0.05)$.

Overexpression of ERP57 can promote folding and trafficking of WT/A561V mutant protein. In the WT/A561V cell group (Fig. 5A), the immature form of HERG protein in the ERP57 overexpression group was increased compared with that in other groups $(\mathrm{P}<0.05)$, indicating that ERP57 overexpression can promote the correct folding of protein. ERP57 expression, as measured by RT-qPCR (Fig. 5B), was increased compared with the Vector group $(\mathrm{P}<0.001)$. After plasma membrane 

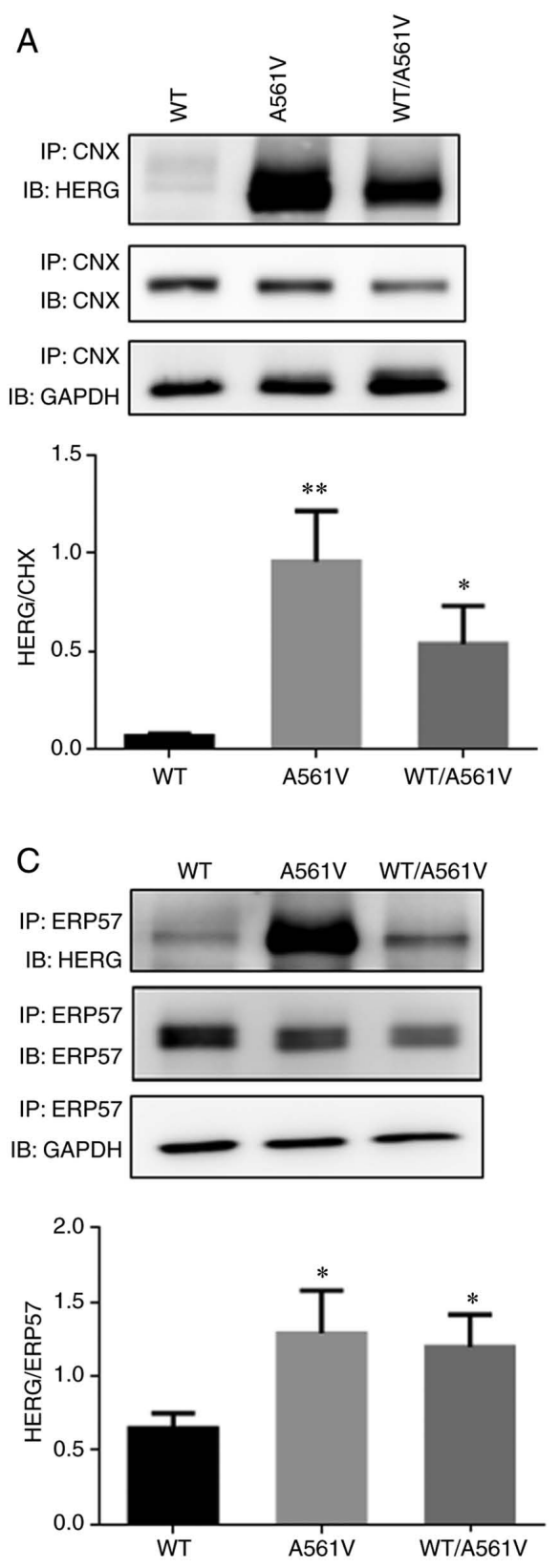

B
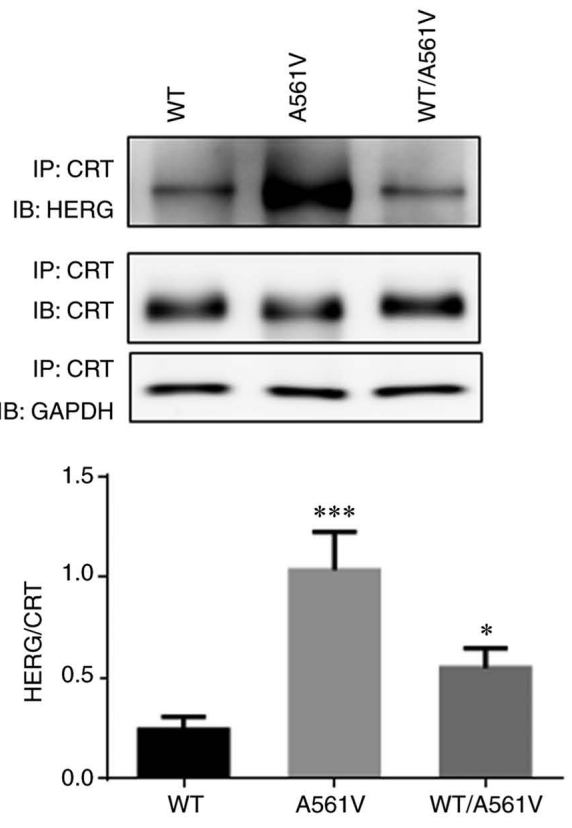

D
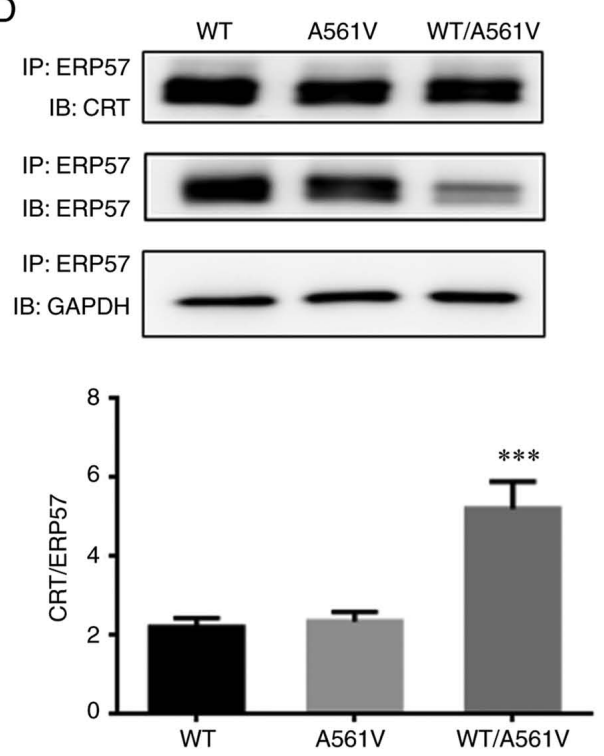

Figure 3. Mutual binding of A561V and WT/A561V proteins with molecular chaperones CNX/ERP57/CRT was significantly increased compared with the WT group. (A) HERG and CNX binding and optical density analysis. ${ }^{*} \mathrm{P}<0.05,{ }^{* *} \mathrm{P}<0.01$ vs. WT. (B) HERG and CRT binding and optical density analysis. ${ }^{*} \mathrm{P}<0.05$, ${ }^{* * * *} \mathrm{P}<0.001$ vs. WT. (C) HERG and ERP57 binding and optical density analysis. "P<0.05 vs. WT. (D) CRT and ERP57 binding and optical density analysis. ${ }^{* * * *} \mathrm{P}<0.001$ vs. WT. Data are presented as the mean $\pm \mathrm{SD} ; \mathrm{n}=3$ in each group. One-way ANOVA was used to analyze the data. CNX, calnexin; CRT, calreticulin; ERP57, endoplasmic reticulum protein 57; HERG, human ether-a-go-go-related gene; IB, antibody used to blot the membrane; IP, lysate after incubation with antibody and pulled down using beads; WT, wild-type HERG group; A561V, A561V-HERG mutation group; WT/A561V, heterozygous HERG group.

separation (Fig. 5C and D), western blotting revealed that not only immature form expression of HERG protein in the cytoplasm increased $(\mathrm{P}<0.05)$ but the expression levels of mature form of HERG protein on the membrane were also increased $(\mathrm{P}<0.05)$.

Overexpression of CRT can help the folding of WT/A561V mutant protein but knockdown of CRT cannot. Relative CRT mRNA expression, as measured by RT-qPCR, was increased compared with the Vector group $(\mathrm{P}<0.001$; Fig. 6A). In WT/A561V cells, the expression levels of the immature form of HERG in the CRT-overexpressing group were significantly increased $(\mathrm{P}<0.05)$, and the mature form of HERG protein did not increase significantly ( $\mathrm{P}>0.05$; Fig. 6B). Additionally, relative CRT mRNA expression (Fig. 6C) was decreased compared with the Vector group $(\mathrm{P}<0.05)$. The expression levels of immature and mature forms of HERG in the knockdown of CRT protein group were significantly lower than those in the control group ( $\mathrm{P}<0.05$; Fig. 6D). After plasma membrane separation, as shown in Fig. $6 \mathrm{E}$ and $\mathrm{F}$, the HERG protein expression in the cytoplasm was significantly increased in the CRT overexpression group $(\mathrm{P}<0.05)$, and that on the membrane did not increase significantly in the CRT overexpression group $(\mathrm{P}>0.05)$. As shown in Fig. $6 \mathrm{G}$ and $\mathrm{H}$, HERG protein expression in the cytoplasm was significantly reduced in the knockdown of CRT group $(\mathrm{P}<0.05)$, and that 
A
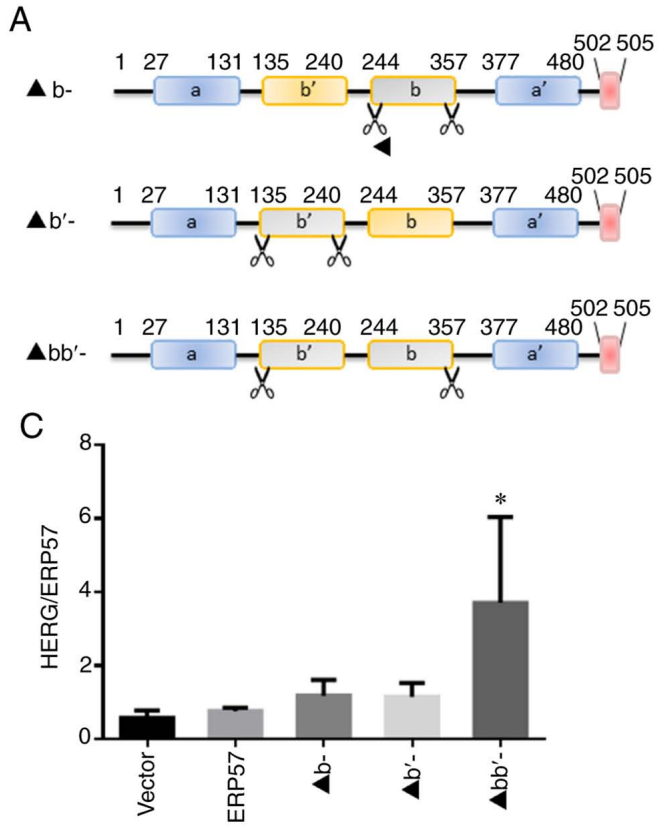

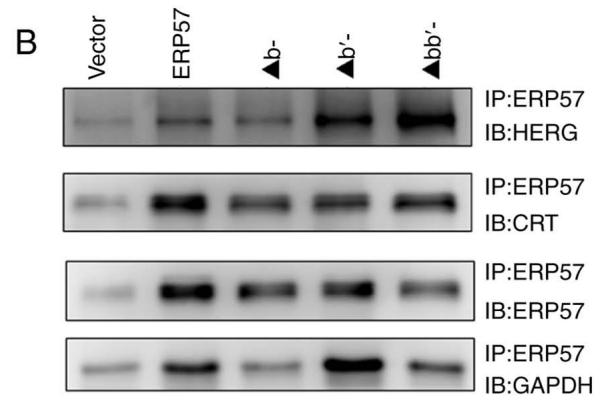

D

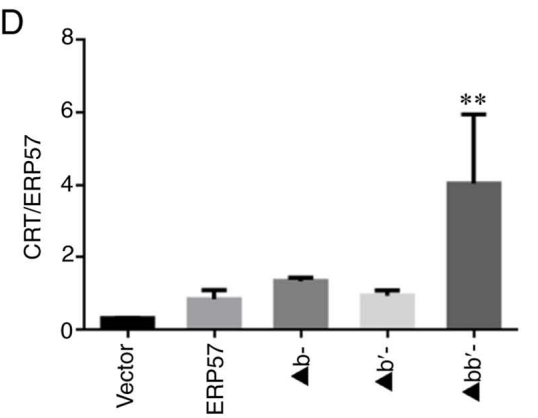

Figure 4. bb' domain of ERP57 is a key domain that binds to HERG and CRT proteins. (A) Specific location of ERP57 domain deletion. (B) After modified ERP57 was expressed in WT/A561V cells, ERP57 binding to HERG and CRT was detected. Optical density analysis of (C) HERG and (D) CRT binding to modified ERP57, including ERP57 lacking its b and b' domains. Data are presented as the mean \pm SD; $n=3$ in each group. One-way ANOVA was used to analyze the data. ${ }^{*} \mathrm{P}<0.05,{ }^{* *} \mathrm{P}<0.01$ vs. vector group. b-, ERP57 b-domain deletion group; $\boldsymbol{\Delta}$ b'-, ERP57 b'-domain deletion group; $\boldsymbol{\Delta}$ bb'-, ERP57 bb'-domain deletion group; CRT, calreticulin; ERP57, endoplasmic reticulum protein 57; HERG, human ether-a-go-go-related gene; IB, antibody used to blot the membrane; IP, lysate after incubation with antibody and pulled down using beads; WT, wild-type.

on the membrane was significantly reduced in the knockdown of CRT group $(\mathrm{P}<0.05)$. The present study revealed that CRT overexpression promoted the correct folding and trafficking of the immature form of HERG. Furthermore, knockdown of CRT reduced the expression of both the mature and immature forms of HERG protein, and failed to serve a role in the correct folding and trafficking of WT/A561V protein.

Overexpression of CRT and ERP57 can increase the tail current density of $W T / A 561 \mathrm{~V}$. Confocal images clearly demonstrated that overexpression of CRT and ERP57 increased HERG protein localization in the plasma membrane (Fig. 7A-C). As shown in Fig. 7H, the tail current amplitude of the CRT overexpression group $(19.48 \pm 7.48 \mathrm{pA} / \mathrm{pF})$ increased by $46 \%$ compared with the heterozygous control group $(13.30 \pm 3.23 \mathrm{pA} / \mathrm{pF} ; \mathrm{n}=6 ; \mathrm{P}<0.05)$, and the tail current amplitude of the ERP57 overexpression group $(20.41 \pm 4.07 \mathrm{pA} / \mathrm{pF})$ increased by $53 \%$ compared with the heterozygous control group $(13.30 \pm 3.23 \mathrm{pA} / \mathrm{pF} ; \mathrm{n}=6 ; \mathrm{P}<0.05)$. In Fig. 7I, the normalized data of the tail currents were plotted against the test potential and fitted to a Boltzmann function. The half-maximal activation voltage (V1/2) in WT/A561V cells was $-17.19709 \pm 2.22513 \mathrm{mV}$, whereas that in WT/A561V+CRT cells was $-18.57577 \pm 1.16886 \mathrm{mV}(\mathrm{n}=6 ; \mathrm{P}>0.05)$, and that in WT/A561V cells was $-17.19709 \pm 2.22513 \mathrm{mV}$, whereas that in WT/A561V+ERP57 cells was $-21.63619 \pm 1.42333 \mathrm{mV} \quad(\mathrm{n}=6$; $\mathrm{P}>0.05)$. A similar trend was seen in the slope factor $\mathrm{k}$ values of WT/A561V cells $(7.87613 \pm 1.95185 \mathrm{mV})$ compared with WT/A561V+CRT cells $(9.45329 \pm 1.02986 \mathrm{mV} ; \mathrm{n}=6 ; \mathrm{P}>0.05)$, and WT/A561V cells $(7.87613 \pm 1.95185 \mathrm{mV})$ compared with WT/A561V+ERP57 cells $(10.86673 \pm 1.2318 \mathrm{mV} ; \mathrm{n}=6$; P>0.05). Therefore, there was no significant difference in activation phase properties among the CRT overexpression, ERP57 overexpression and WT/A561V groups. The heterozygous channel did not completely lose its function. If it can partially resume normal transport after its regulation, it can still perform a certain compensatory function. These results suggested that overexpression of key molecular chaperones, including CRT and ERP57, could correct the function of the WT/A561V channel.

\section{Discussion}

The HERG channel protein is a glycosylated protein composed of four $\alpha$ subunits (3). The channel protein-peptide chain enters the ER after ribosome synthesis and undergoes core glycosylation at position N598 to form a $135 \mathrm{kDa}$ precursor (23). The precursor is then transported to the Golgi apparatus and undergoes complex glycosylation to form a $155 \mathrm{kDa}$ mature channel protein inserted into the cell membrane (24). Compared with WT HERG, represented on a western blot by a $155-\mathrm{kDa}$ band of mature HERG channel protein, the mutant HERG protein, represented on a western blot by a $135-\mathrm{kDa}$ immature HERG protein band, is prone to misfolding and is retained in the ER (25). The mutant channel protein will combine with the WT protein to form a hybrid channel, producing two protein bands of 155 and $135 \mathrm{kDa}$ on a western blot, and stay in the ER, thereby reducing the expression of the WT protein in the cell membrane (19). These mutant proteins, especially heterozygous channels, are not completely non-functional (5). If their normal transport can be partially restored by overexpression of related chaperones, the mutant protein can still perform a compensatory function (26). In other words, the upstream regulatory mechanism of HERG channel abnormalities is the 

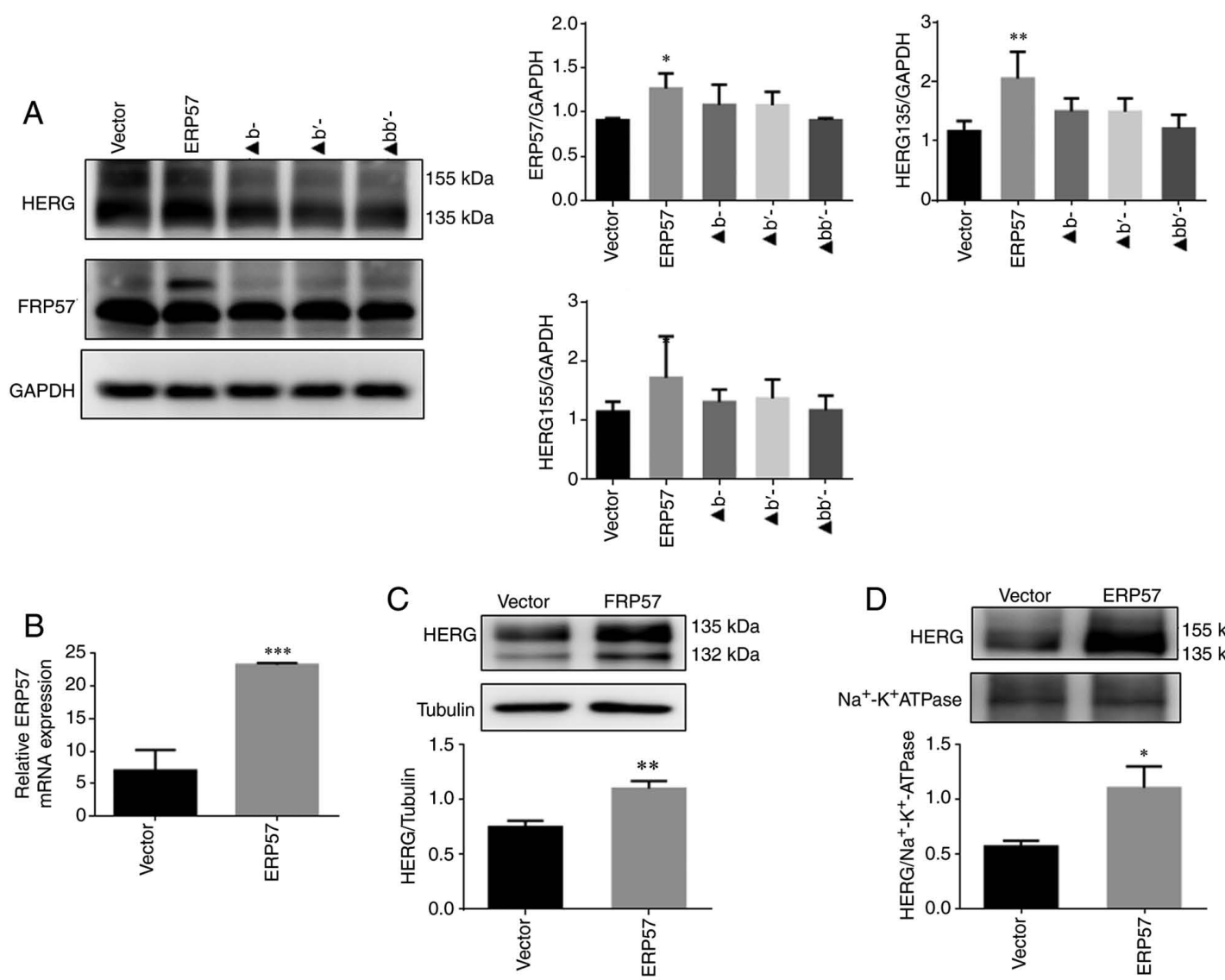

Figure 5. Overexpression of ERP57 can promote folding and trafficking of WT/A561V mutant protein. (A) Expression levels of HERG and ERP57 protein in WT/A561V cells after expression of modified ERP57. Optical density analysis of ERP57 in cells overexpressing ERP57. One-way ANOVA was used to analyze the data. ${ }^{*} \mathrm{P}<0.05$ vs. vector group. Optical density analysis of the $135-\mathrm{kDa}$ immature form of HERG in WT/A561V cells overexpressing ERP57. "P $<0.05$ vs. vector group. Optical density analysis of the 155-kDa mature form of HERG $(\mathrm{P}>0.05)$. (B) Relative ERP57 mRNA expression in cells overexpressing ERP57. An unpaired Student's t-test was used to analyze the data. ${ }^{* * *} \mathrm{P}<0.001$. (C) Optical density analysis of the 135 -kDa immature form of HERG in the cytoplasm after overexpression of ERP57 in WT/A561V cells overexpressing ERP57. An unpaired Student's t-test was used to analyze the data. ${ }^{* *} \mathrm{P}<0.01$. (D) Optical density analysis of $155-\mathrm{kDa}$ mature form of HERG in the cell membrane after overexpression of ERP57 in WT/A561V cells overexpressing ERP57. An unpaired Student's t-test was used to analyze the data. "P<0.05. Data are presented as the mean \pm SD; $n=3$ in each group. $\mathbf{\Delta b -}$, ERP57 b-domain deletion group; $\mathbf{\Delta}$ b'-, ERP57 b'-domain deletion group; $\mathbf{\Delta}$ bb'-, ERP57 bb'-domain deletion group; ERP57, endoplasmic reticulum protein 57; HERG, human ether-a-go-go-related gene; WT, wild-type.

ERQC system, which mediates channel protein folding and transport in the ER, and serves a vital role in changes in ion channel function (27). The aforementioned viewpoints were verified in the present study.

The CNX/CRT cycle is an essential part of the ERQC system and one of the critical mechanisms for monitoring protein folding and assembly (17). The disulfide bond isomerase ERP57 can form transient disulfide bonds with CNX/CRT-bound glycoproteins to facilitate protein folding $(13,14)$, and the $\mathrm{b}$ and $b^{\prime}$ domains of ERP57 protein contain the binding sites for CRT and CNX. UDP-glucose: Glycoprotein glucosyltransferase 1 (UGGT1) is an important enzyme in the circulatory system and can specifically recognize incompletely folded proteins and catalyze their glycosylation, which is called the ER folding induction device $(28,29)$. Once the glycoprotein is misfolded, Man9GlcNAc2 will add glucose under UGGT1 catalysis, and the protein will re-enter the CNX/CRT cycle for refolding (30). If the protein still fails to fold correctly, to avoid excessive accumulation of misfolded protein in the ER, it will be released from the CNX/CRT cycle under the action of ER mannosidase I, and the mannosidase, which enhances ER degradation enzyme-like protein is combined and degraded through ER-associated degradation (31-34). The specific process is shown in Fig. 8.

To study the role of the chaperone proteins CNX, CRT and ERP57 in the process of A561V trafficking and defects, the present study examined the expression levels of HERG protein and CNX/CRT/ERP57 in WT, A561V and WT/A561V cells. The data revealed that immature HERG protein expression was significantly increased in A561V and WT/A561V cells compared with its expression in WT cells and the expression of molecular chaperones CNX and CRT was also significantly increased compared with their expression in WT cells, and ERP57 was significantly increased in WT/A561V cells compared with WT cells. This result indicated that molecular chaperones CNX, CRT and ERP57 serve a role in the A561V transport process. Furthermore, the CNX/CRT chaperone role in the A561V mutant was consistent with the results obtained for E637K-HERG and G572R-HERG mutants (24).

To the best of our knowledge, the present study demonstrated for the first time that folding and maturation of A561V were controlled by cytoplasmic chaperone ERP57 and verified the key domains of ERP57 protein and its specific mechanism of action. Currently, ERP57 protein is primarily used in tumor 
A
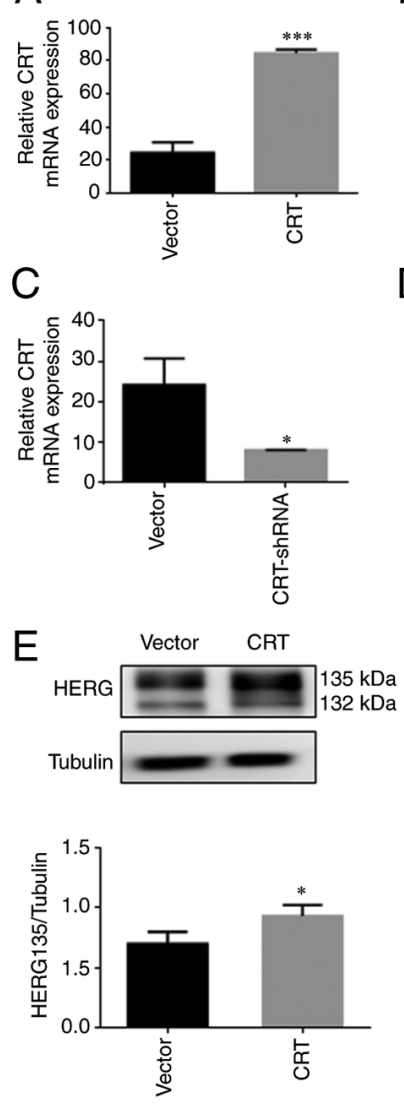

B
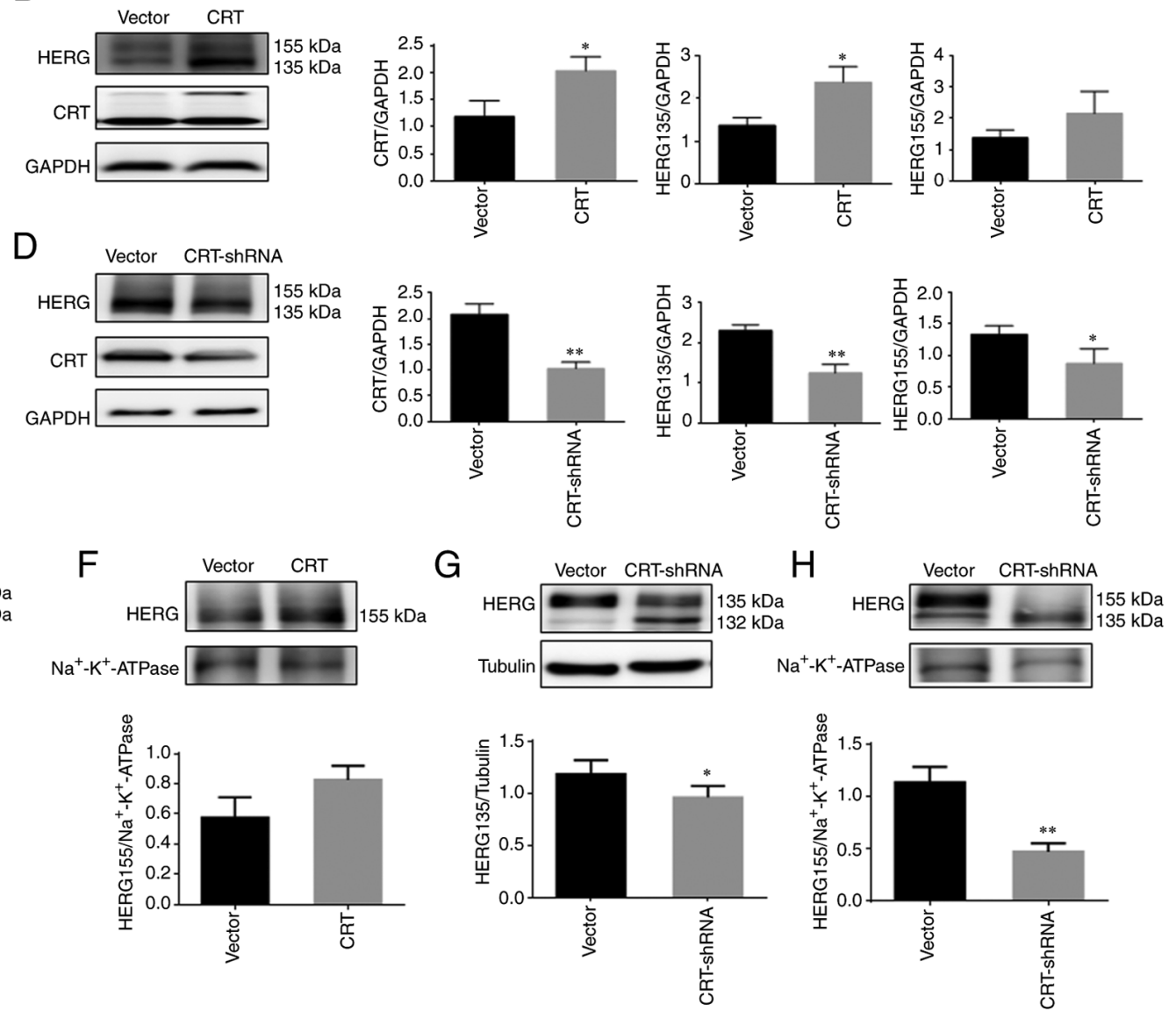

Figure 6. In WT/A561V cells, the expression levels of the immature form of HERG in the CRT-overexpressing group were significantly increased, and the mature form of HERG protein did not increase significantly. The expression levels of immature and mature forms of HERG in the knockdown of CRT protein group were significantly lower than those of the control group. (A) Relative CRT mRNA expression in cells overexpressing CRT. ${ }^{* * *} \mathrm{P}<0.001$. (B) Expression levels of HERG and CRT in WT/A561V cells after CRT overexpression. Optical density analysis of CRT in cells overexpressing CRT. * $<0.05$. In cells overexpressing CRT, optical density analysis was performed on the immature form of HERG protein $\left(135 \mathrm{kDa}\right.$; $\left.{ }^{*}<0.05\right)$ and on the mature form of HERG protein (155 kDa; P>0.05). (C) Relative CRT mRNA expression in cells transfected with CRT-shRNA. *P<0.05. (D) Expression levels of HERG and CRT proteins in WT/A561V cells after knockdown of CRT. Optical density analysis of CRT protein in cells with knockdown of CRT. ${ }^{* *} \mathrm{P}<0.01$. In cells with knockdown of CRT, optical density analysis was performed on the immature form of HERG protein $\left(135 \mathrm{kDa} ;{ }^{* *} \mathrm{P}<0.01\right)$ and on the mature form of $\mathrm{HERG}$ protein $(155 \mathrm{kDa}$; $\left.{ }^{*} \mathrm{P}<0.05\right)$. (E) Optical density analysis of the immature form of HERG protein ( $\left.135 \mathrm{kDa}\right)$ in the cytoplasm of cells overexpressing CRT. ${ }^{*} \mathrm{P}<0.05$. (F) Optical density analysis of the mature form of HERG protein $(155 \mathrm{kDa})$ in the cell membrane of cells overexpressing CRT (P>0.05). (G) Optical density analysis of the immature form of HERG protein $(135 \mathrm{kDa})$ in the cytoplasm of cells with knockdown of CRT. * P $<0.05$. (H) Optical density analysis of the mature form of HERG protein $(155 \mathrm{kDa})$ in the cell membrane of cells with knockdown of CRT. ${ }^{* *} \mathrm{P}<0.01$. Data are presented as the mean $\pm \mathrm{SD}$; $\mathrm{n}=3$ in each group. An unpaired Student's t-test was used to analyze the data. CRT, calreticulin; HERG, human ether-a-go-go-related gene; shRNA, short hairpin RNA; WT, wild-type.

research. ERP57 is abnormally dysregulated in a number of cancer types, including cervical cancer and laryngeal cancer, and abnormal ERP57 expression has been evaluated as a clinical prognostic indicator (35). Upregulation or downregulation of ERP57 may be associated with poor prognosis (36). Furthermore, CRT protein, the key molecular chaperone in the CNX/CRT protein cycle, is one of the main calcium-binding proteins in the ER (37). In addition to coordinating membrane surface and exocrine proteins in the ER, CRT can also help the folding and trafficking of misfolded proteins retained in the ER (38). However, a recent study has revealed that CRT is not only present in the ER but also localizes to the cell membrane and is secreted to the outside of the cell to perform its specific functions (39). In the future, it will be necessary to conduct experiments to determine whether these functions are also involved in folding and transportation of HERG protein.

Accumulating misfolded proteins is a major feature of pathology of numerous neurodegenerative diseases, including frontotemporal dementia, amyotrophic lateral sclerosis, Parkinson's disease, Alzheimer's Mer's disease, Huntington's disease and Creutzfeldt-Jakob disease (16). ER stress and activation of unfolded protein response after misfolding and/or nascent protein accumulation are common features in the cytopathology of these diseases, which is the pathology of accumulating mutant proteins or misfolded proteins in the ER caused by mutations in HERG gene features (40). However, the cumulative effect of activating the unfolded protein response depends on integrating cell survival time and the duration of apoptosis signals (41). Activation of the unfolded protein response will increase the recruitment of PDI family members to promote protein folding or trigger cell apoptosis (42). In Creutzfeldt-Jakob disease, ERP57 upregulation is considered a defense response against toxicity of misfolded prion virus protein (43). However, characterization of the role of ERP57 in mediating the steady-state levels of WT and prion virus-associated disease related mutant proteins suggests that 
A
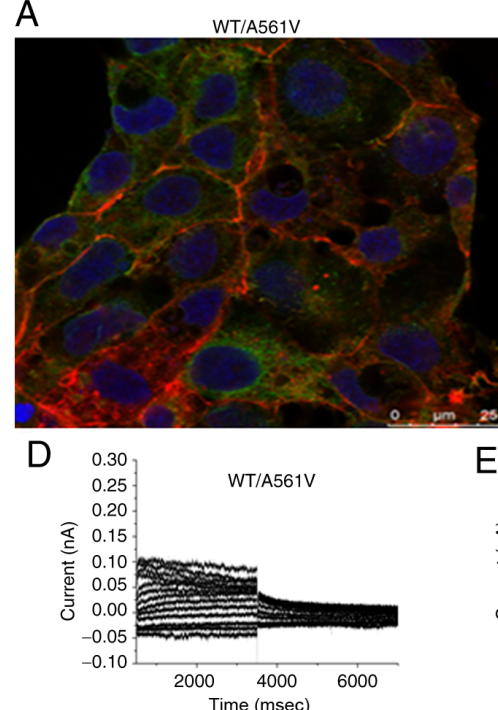

G

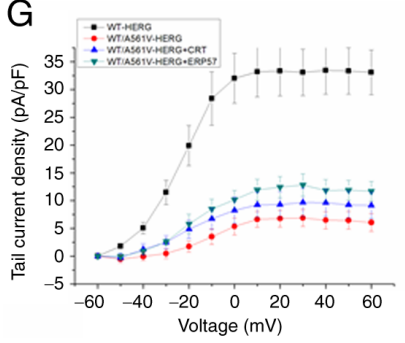

$\mathrm{E}$

$\mathrm{H}$
B
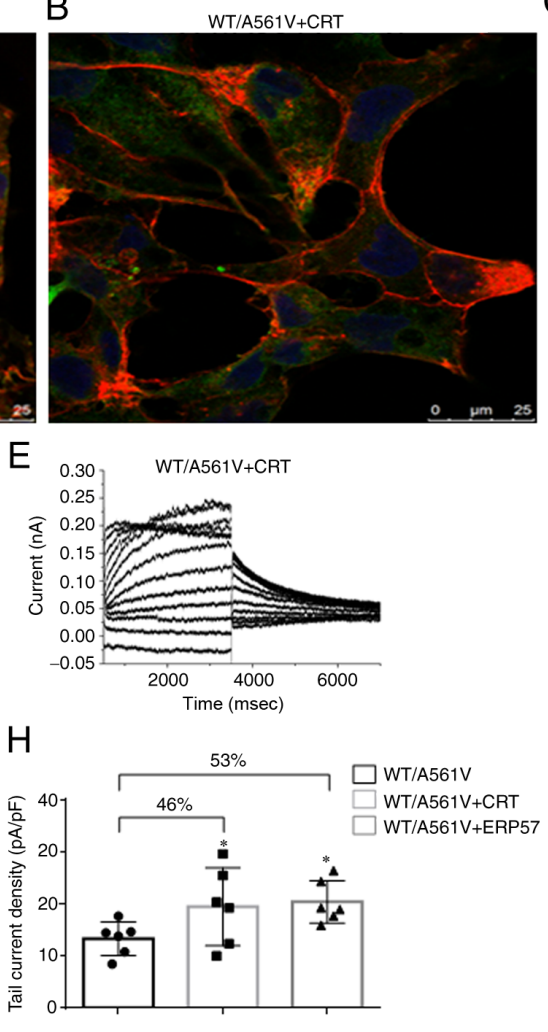

C

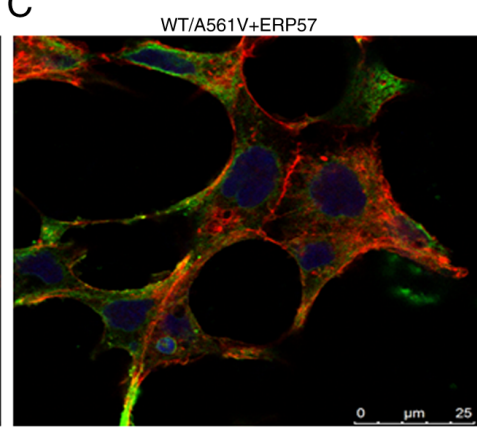

F

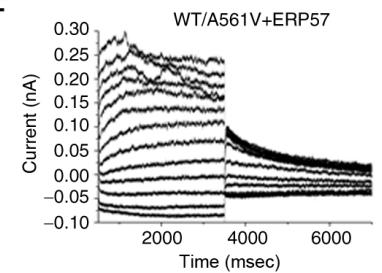

I

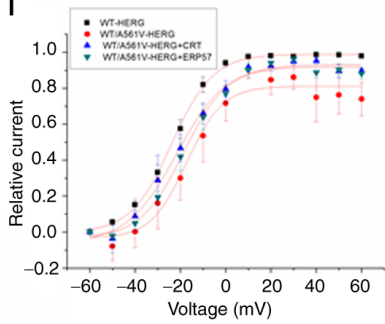

Figure 7. Overexpression of CRT and ERP57 can increase the tail current density of WT/A561V. (A) Confocal imaging of WT/A561V channel in 293 cells (60X confocal special oil lens). (B) Confocal imaging of WT/A561V channel in 293 cells overexpressing CRT protein (60X confocal special oil lens). (C) Confocal imaging of WT/A561V channel in 293 cells overexpressing ERP57 protein (60X confocal special oil lens). Co-staining with anti-HERG antibody (green), DAPI-stained nuclei (blue) and phalloidin (red). (D) Tail current amplitudes of WT/A561V group. (E) Tail current amplitudes of CRT overexpression group. (F) Tail current amplitudes of ERP57 overexpression group. (G) Current density-voltage relationship for tail currents amplitudes of WT, WT/A561V, overexpression of CRT and overexpression of ERP57 groups. (H) Statistical graph of tail current amplitudes. The tail current amplitudes of the CRT group were increased by $46 \%$ compared with the WT/A561V group $\left(\mathrm{n}=6\right.$; $\left.{ }^{*} \mathrm{P}<0.05\right)$. The tail current amplitudes of the ERP57 group were increased by 53\% compared with the WT/A561V group $(\mathrm{n}=6$; " $\mathrm{P}<0.05)$. (I) Amplitudes of tail currents of WT, WT/A561V, WT/A561V+CRT, WT/A561V+ERP57 channel plotted as a function of the test potential and fitted to a Boltzmann function ( $\mathrm{n}=6$ ). CRT, calreticulin; ERP57, endoplasmic reticulum protein 57; HERG, human ether-a-go-go-related gene; WT, wild-type.

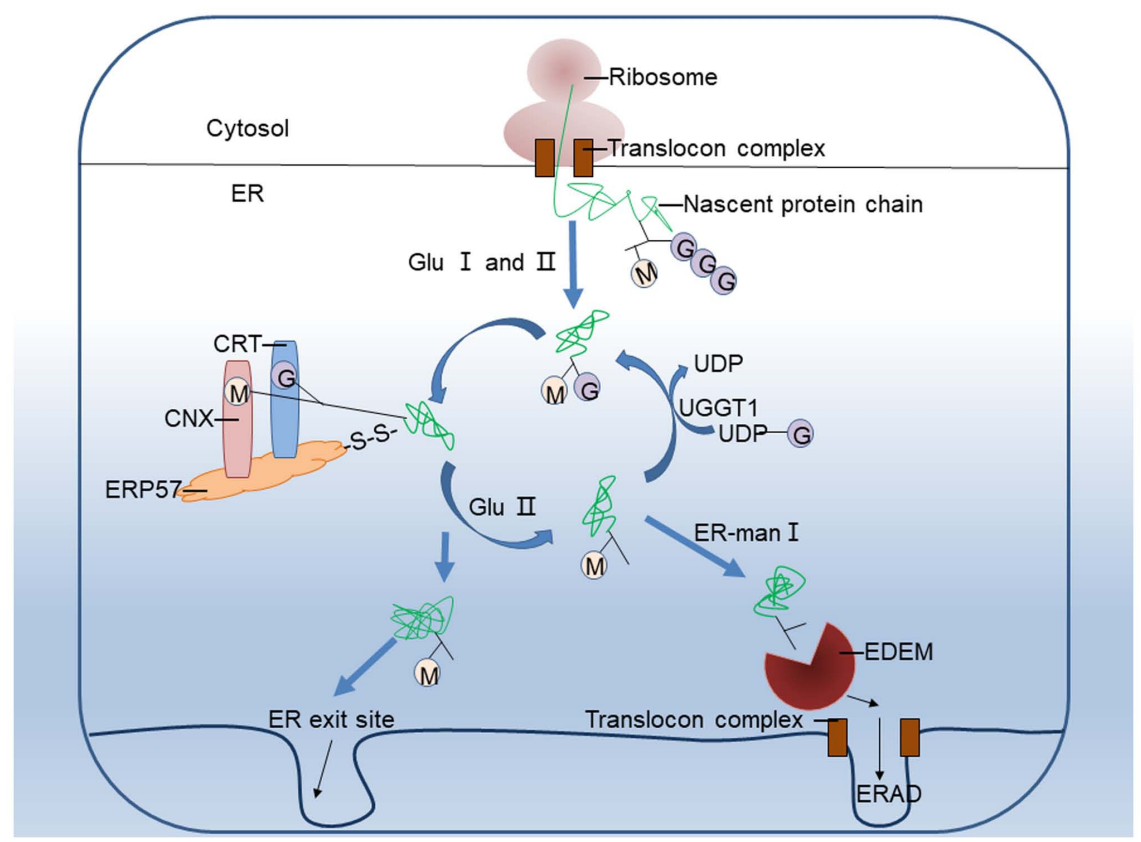

Figure 8. CNX/CRT cycle is an important part of the ERQC system, and its key proteins are CNX, CRT, ERP57, UGGT1, Glu II, ER-man I and EDEM, all of which are involved in the process of protein folding and transport. CNX, calnexin; CRT, calreticulin; ERP57, endoplasmic reticulum protein 57; ER, endoplasmic reticulum; ERQC, ER quality control; ERAD, ER-associated degradation; GluI/II, glucosidases I/II; UGGT1, UDP-glucose: Glycoprotein glucosyltransferase 1; ER-man I, endoplasmic reticulum-mannosidase I; EDEM, ER degradation-enhancing $\alpha$-mannosidase-like protein. 
ERP57 deficiency may cause prion virus protein folding but may not contribute to resistance to ER stress sensitivity (44). The ability to inhibit mutant huntingtin-mediated toxicity by inhibiting ERP57 and/or PDI highlights that PDI can promote apoptosis by stimulating mitochondrial outer membrane permeability (MOMP) to stimulate neurodegenerative diseases with abnormal cytoplasmic protein aggregation characteristics (45). In the present study, upregulation of ERP57 promoted the correct folding and transportation of misfolded and unfolded proteins. ERP57 may be upregulated during ER stress as part of a protective response to promote the folding of aggregated proteins and restore cellular protein stability. Simultaneously, excessive ERP57 can stimulate cell apoptosis through MOMP. Notably, ERP57 is a selective folding enzyme that only interacts with a part of potential protein aggregates (46). It is unclear whether ERP57 can protect HERG mutant protein or other aggregation-prone proteins involved in misfolding in vivo, or if ERP57 can directly rescue the mutant conformation of HERG protein. Investigation of this will reveal the potential of ERP57 as a possible therapeutic target for LQTS caused by mutations in the HERG gene.

The present study detected no $I K r$ current in A561V cells in which A561V was transported from the ER to the cell membrane. This result may be due to mutations in the channel pore area and channel opening, preventing potassium ions from passing through the channel. The function of the WT/A561V heterozygous channel was not completely abolished. An $I K r$ current was detected; however, it was weaker than the tail current of the WT HERG channel, so it would be important to correct the $I K r$ current of the heterozygous HERG channel. For this reason, the expression of molecular chaperones was adjusted to interfere with folding and transportation of the WT/A561V channel protein. It was revealed that knockdown of CRT protein did not promote HERG protein transport to the membrane, while CRT and ERP57 overexpression promoted the correct folding and transport of the protein. Knockdown of CRT can lead to non-apoptotic cell death, leading to complete cell disintegration (47), consistent with reduced expression levels of mature and immature HERG protein forms after knockdown of CRT protein. In the overexpression group, the amounts of immature $(135 \mathrm{kDa})$ and mature forms $(155 \mathrm{kDa})$ of HERG protein were increased to varying degrees in the cytoplasm and membrane. To verify the impact of overexpression of CRT and ERP57 in the WT/A561V cell model, whole-cell patch-clamp technology was used to detect the $I K r$ current in cells from each group, indicating that overexpression of CRT and ERP57 further corrected the WT/A561V trafficking defect.

The present study clarified the specific role of the CNX/CRT cycle in mediating the folding and transport of WT and mutant HERG and analyzed the regulatory roles of key factors CNX, CRT and ERP57 in binding HERG protein and HERG channel function. It was revealed that these factors can change the transport process of proteins, especially heterozygous mutant proteins, by improving HERG channel protein transport and increasing HERG channel protein function, suggesting novel avenues for developing treatments for LQTS from the perspective of correcting protein transport defects. The present study demonstrated that the three chaperone proteins, CNX, CRT and ERP57, block the mutant protein in the ER and refold it into its correct conformation, which serves a crucial role in trafficking the A561V mutant protein. Additionally, overexpression of CRT and ERP57 promoted the correct transport of WT/A561V and restored its function. This potential therapeutic method may also provide ideas for treating other clinically relevant protein trafficking diseases.

\section{Acknowledgements}

Not applicable.

\section{Funding}

This work was supported by the National Natural Science Foundation of China (grant no. 81870255); the Natural Science Foundation of the Zhejiang Province (grant no. LY21H020001); the Medical Health Science and Technology Project of Zhejiang Provincial Health Commission (grant no. 2021KY306); the Natural Science Foundation of Ningbo (grant nos. 2019A610340, 2019A610341, 2018A610398 and 2015A610180).

\section{Availability of data and materials}

The datasets used and/or analyzed during the current study are available from the corresponding author on reasonable request.

\section{Authors' contributions}

$\mathrm{XH}, \mathrm{XY}$ and JL conceived and designed the experiments. YW, YB and ZZ performed the experiments, YW and YB analyzed the data. XH and JL contributed reagents and materials. YW, $\mathrm{XH}$ and JL wrote the paper. YW and JL confirm the authenticity of all the raw data. All authors read and approved the final manuscript.

\section{Ethics approval and consent to participate}

Not applicable.

\section{Patient consent for publication}

Not applicable.

\section{Competing interests}

The authors declare that they have no competing interests.

\section{References}

1. Wallace E, Howard L, Liu M, O'Brien T, Ward D, Shen S and Prendiville T: Long QT syndrome: Genetics and future perspective. Pediatr Cardiol 40: 1419-1430, 2019.

2. Kanner SA, Jain A and Colecraft HM: Development of a high-throughput flow cytometry assay to monitor defective trafficking and rescue of long QT2 mutant hERG channels. Front Physiol 9: 397, 2018.

3. Butler A, Helliwell MV, Zhang Y, Hancox JC and Dempsey CE: An update on the structure of hERG. Front Pharmacol 10: 1572, 2020.

4. Perissinotti L, Guo J, Kudaibergenova M, Lees-Miller J, Ol'khovich M, Sharapova A, Perlovich GL, Muruve DA, Gerull B, Noskov SY and Duff HJ: The pore-lipid interface: Role of amino-acid determinants of lipophilic access by ivabradine to the hERG1 pore domain. Mol Pharmacol 96: 259-271, 2019. 
5. Zhang KP, Yang BF and Li BX: Translational toxicology and rescue strategies of the hERG channel dysfunction: Biochemical and molecular mechanistic aspects. Acta Pharmacol Sin 35: 1473-1484, 2014

6. Li G, Shi R, Wu J, Han W, Zhang A, Cheng G, Xue X and Sun C: Association of the hERG mutation with long-QT syndrome type 2, syncope and epilepsy. Mol Med Rep 13: 2467-2475, 2016.

7. Foo B, Williamson B, Young JC, Lukacs G and Shrier A hERG quality control and the long QT syndrome. J Physiol 594: 2469-2481, 2016.

8. Araki K and Nagata K: Protein folding and quality control in the ER. Cold Spring Harb Perspect Biol 3: a007526, 2011.

9. Marti L, Lia A, Reca IB, Roversi P, Santino A and Zitzmann N: In planta preliminary screening of ER glycoprotein folding quality control (ERQC) modulators. Int J Mol Sci 19: 2135, 2018

10. Lamothe SM, Hulbert M, Guo J, Li W, Yang T and Zhang S: Glycosylation stabilizes hERG channels on the plasma membrane by decreasing proteolytic susceptibility. FASEB J 32: 1933-1943, 2018.

11. Patel C, Saad H, Shenkman M and Lederkremer GZ: Oxidoreductases in glycoprotein glycosylation, folding, and ERAD. Cells 9: 2138, 2020.

12. Tannous A, Pisoni GB, Hebert DN and Molinari M: N-linked sugar-regulated protein folding and quality control in the ER. Semin Cell Dev Biol 41: 79-89, 2015.

13. Foo B, Barbier C, Guo K, Vasantharuban J, Lukacs GL and Shrier A: Mutation-specific peripheral and ER quality control of hERG channel cell-surface expression. Sci Rep 9: 6066, 2019

14. Shi YQ, Yan M, Liu LR, Zhang X, Wang X, Geng HZ, Zhao X and Li BX: High glucose represses hERG K+ channel expression through trafficking inhibition. Cell Physiol Biochem 37: 284-296, 2015

15. Hettinghouse A, Liu R and Liu CJ: Multifunctional molecule ERp57: From cancer to neurodegenerative diseases. Pharmacol Ther 181: 34-48, 2018.

16. Song D, Liu H, Wu J, Gao X, Hao J and Fan D: Insights into the role of ERp57 in cancer. J Cancer 12: 2456-2464, 2021.

17. Kozlov G and Gehring K: Calnexin cycle-structural features of the ER chaperone system. FEBS J 287: 4322-4340, 2020.

18. Pollock S, Kozlov G, Pelletier MF, Trempe JF, Jansen G, Sitnikov D, Bergeron JJ, Gehring K, Ekiel I and Thomas DY: Specific interaction of ERp57 and calnexin determined by NMR spectroscopy and an ER two-hybrid system. EMBO J 23 1020-1029, 2004.

19. Wang Y, Shen T, Fang P, Zhou J, Lou K, Cen Z, Qian H, Zhou J, Liu N and Lian J: The role and mechanism of chaperones calnexin/calreticulin in which ALLN selectively rescues the trafficking defective of HERG-A561V mutation. Biosci Rep: Sep 7, 2018 (Epub ahead of print).

20. Livak KJ and Schmittgen TD: Analysis of relative gene expression data using real-time quantitative PCR and the 2(-Delta Delta C(T)) method. Methods 25: 402-408, 2001.

21. Smith JL, Anderson CL, Burgess DE, Elayi CS, January CT and Delisle BP: Molecular pathogenesis of long QT syndrome type 2. J Arrhythm 32: 373-380, 2016.

22. Jenewein T, Kanner SA, Bauer D, Hertel B, Colecraft HM, Moroni A, Thiel G and Kauferstein S: The mutation L69P in the PAS domain of the hERG potassium channel results in LQTS by trafficking deficiency. Channels (Austin) 14: 163-174, 2020.

23. Zhan G, Wang F, Ding YQ, Li XH, Li YX, Zhao ZR, Li JX, Liu Y, Zhao X, Yan CC and Li BX: Rutaecarpine targets hERG channels and participates in regulating electrophysiological properties leading to ventricular arrhythmia. J Cell Mol Med 25: 4938-4949, 2021.

24. Wang Y, Huang X, Zhou J, Yang X, Li D, Mao H, Sun HH, Liu N and Lian J: Trafficking-deficient G572R-hERG and E637K-hERG activate stress and clearance pathways in endoplasmic reticulum. PLoS One 7: e29885, 2012.

25. Ono M, Burgess DE, Schroder EA, Elayi CS, Anderson CL, January CT, Sun B, Immadisetty K, Kekenes-Huskey PM and Delisle BP: Long QT syndrome type 2: Emerging strategies for correcting class $2 \mathrm{KCNH} 2$ (hERG) mutations and identifying new patients. Biomolecules 10: 1144, 2020.

26. Anderson CL, Delisle BP, Anson BD, Kilby JA, Will ML, Tester DJ, Gong Q, Zhou Z, Ackerman MJ and January CT: Most LQT2 mutations reduce Kv11.1 (hERG) current by a class 2 (trafficking-deficient) mechanism. Circulation 113: 365-373, 2006.

27. Du H, Zheng C, Aslam M, Xie X, Wang W, Yang Y and Liu X: Endoplasmic reticulum-mediated protein quality control and endoplasmic reticulum-associated degradation pathway explain the reduction of $\mathrm{N}$-glycoprotein level under the lead stress. Front Plant Sci 11: 598552, 2021.
28. Ito Y, Takeda Y, Seko A, Izumi M and Kajihara Y: Functional analysis of endoplasmic reticulum glucosyltransferase (UGGT): Synthetic chemistry's initiative in glycobiology. Semin Cell Dev Biol 41: 90-98, 2015.

29. Tannous A, Patel N, Tamura T and Hebert DN: Reglucosylation by UDP-glucose: Glycoprotein glucosyltransferase 1 delays glycoprotein secretion but not degradation. Mol Biol Cell 26 390-405, 2015.

30. Ferris SP, Jaber NS, Molinari M, Arvan P and Kaufman RJ: UDP-glucose: Glycoprotein glucosyltransferase (UGGT1) promotes substrate solubility in the endoplasmic reticulum. Mol Biol Cell 24: 2597-2608, 2013.

31. Guerriero CJ and Brodsky JL: The delicate balance between secreted protein folding and endoplasmic reticulum-associated degradation in human physiology. Physiol Rev 92: 537-576, 2012

32. Shenkman M, Ron E, Yehuda R, Benyair R, Khalaila I and Lederkremer GZ: Mannosidase activity of EDEM1 and EDEM2 depends on an unfolded state of their glycoprotein substrates. Commun Biol 1: 172, 2018

33. Benyair R, Ogen-Shtern N, Mazkereth N, Shai B, Ehrlich M and Lederkremer GZ: Mammalian ER mannosidase I resides in quality control vesicles, where it encounters its glycoprotein substrates. Mol Biol Cell 26: 172-184, 2015.

34. Ogen-Shtern N, Avezov E, Shenkman M, Benyair R and Lederkremer GZ: Mannosidase IA is in quality control vesicles and participates in glycoprotein targeting to ERAD. J Mol Biol 428: 3194-3205, 2016.

35. Chung H, Cho H, Perry C, Song J, Ylaya K, Lee H and Kim JH: Downregulation of ERp57 expression is associated with poor prognosis in early-stage cervical cancer. Biomarkers 18: 573-579, 2013.

36. Choe MH, Min JW, Jeon HB, Cho DH, Oh JS, Lee HG, Hwang SG An S, Han YH and Kim JS: ERp57 modulates STAT3 activity in radioresistant laryngeal cancer cells and serves as a prognostic marker for laryngeal cancer. Oncotarget 6: 2654-2666, 2015.

37. Kozlov G, Pocanschi CL, Rosenauer A, Bastos-Aristizabal S, Gorelik A, Williams DB and Gehring K: Structural basis of carbohydrate recognition by calreticulin. J Biol Chem 285 : 38612-38620, 2010

38. Kiuchi T, Izumi M, Mukogawa Y, Shimada A, Okamoto R, Seko A, Sakono M, Takeda Y, Ito Y and Kajihara Y: Monitoring of glycoprotein quality control system with a series of chemically synthesized homogeneous native and misfolded glycoproteins J Am Chem Soc 140: 17499-17507, 2018.

39. Ito Y, Kajihara Y and Takeda Y: Chemical-synthesis-based approach to glycoprotein functions in the endoplasmic reticulum. Chemistry 26: 15461-15470, 2020.

40. Ghemrawi R and Khair M: Endoplasmic reticulum stress and unfolded protein response in neurodegenerative diseases. Int J Mol Sci 21: 6127, 2020.

41. Wang SB, Shi Q, Xu Y, Xie WL, Zhang J, Tian C, Guo Y, Wang K, Zhang BY, Chen C, et al: Protein disulfide isomerase regulates endoplasmic reticulum stress and the apoptotic process during prion infection and PrP mutant-induced cytotoxicity. PLoS One 7: e38221, 2012.

42. Perri E, Parakh S and Atkin J: Protein disulphide isomerases: Emerging roles of PDI and ERp57 in the nervous system and as therapeutic targets for ALS. Expert Opin Ther Targets 21: 37-49, 2017.

43. Turano C, Gaucci E, Grillo C and Chichiarelli S: ERp57/GRP58: A protein with multiple functions. Cell Mol Biol Lett 16: 539-563, 2011.

44. Sepulveda M, Rozas P, Hetz C and Medinas DB: ERp57 as a novel cellular factor controlling prion protein biosynthesis: Therapeutic potential of protein disulfide isomerases. Prion 10: 50-56, 2016.

45. Hoffstrom BG, Kaplan A, Letso R, Schmid RS, Turmel GJ, Lo DC and Stockwell BR: Inhibitors of protein disulfide isomerase suppress apoptosis induced by misfolded proteins. Nat Chem Biol 6: 900-906, 2010

46. Grek C and Townsend DM: Protein disulfide isomerase superfamily in disease and the regulation of apoptosis. Endoplasmic Reticulum Stress Dis 1: 4-17, 2014.

47. Han A, Li C, Zahed T, Wong M, Smith I, Hoedel K, Green D and Boiko AD: Calreticulin is a critical cell survival factor in malignant neoplasms. PLoS Biol 17: e3000402, 2019.

This work is licensed under a Creative Commons Attribution-NonCommercial-NoDerivatives 4.0 International (CC BY-NC-ND 4.0) License. 